\title{
FORMACIÓN Y GESTIÓN DEL PATRIMONIO CONVENTUAL FEMENINO: DOS MODELOS CONVERGENTES, SIGLOS XVI-XVIII
}

\author{
Elena Catalán Martínez \\ Universidad del País Vasco UPV/EHU
}

\begin{abstract}
RESumen. El objetivo de este trabajo es realizar un análisis comparativo de las estrategias de formación y consolidación de la propiedad en dos conventos con diferentes marcos legales y económicos. Este estudio muestra que cualquiera que sea el origen y la composición patrimonial de los conventos y monasterios, su gestión estuvo presidida por criterios de rentabilidad económica, mostrando una gran capacidad de adaptación a diferentes situaciones. Contrariamente a la imagen pasiva que ofrece la historiografía, los conventos femeninos mostraron todo el dinamismo posible en una economía preindustrial.
\end{abstract}

Palabras clave: Conventos, señorío, propiedad de la tierra, censos, juros

\begin{abstract}
The aim of this paper is the comparative analysis of the strategies of formation and consolidation of the property in two convents with different legal and economic frameworks. This study shows that whatever the origin and patrimonial composition of convents and monasteries, their management was chaired by criteria of economic profitability, showing a great capacity to adapt to different situations. Contrarily to the passive image offered by historiography, the female convents showed all the possible dynamism in a pre-industrial economy.
\end{abstract}

Keywords: Convents, manor, property, census, juros

Recibido: 10-10-2019 • Aceptado: 26-2-2020 • elena.catalan@ehu.es 
LA DESIGUALDAD económica y la disparidad en la distribución de la renta, propias de las economías preindustriales afectaban por igual a todos los estamentos, fuesen o no privilegiados. En el caso del clero secular, el diezmo marcaba la renta básica a la que tenía derecho cada una de las categorías beneficiales, la cual se complementaba con los ingresos percibidos por el ejercicio de su labor pastoral. En cambio, no existe una base reguladora similar al diezmo que permita categorizar la situación económica del clero regular, especialmente porque todas las órdenes religiosas articularon su discurso económico en torno a la pobreza, aunque la mayoría acabaron administrando importantes patrimonios (Lanzagorta, 2002, pp. 33-35). Así encontramos conventos fundados por las grandes casas nobiliarias que acumularon tierras, fincas urbanas y activos financieros, frente a otros que basaron su economía en la administración de un importante capital mobiliario y cuyos bienes patrimoniales eran escasos.

La historiografía reciente ha superado la imagen de un clero regular, en especial el femenino, improductivo, perceptor de donaciones - o dotes- y con una actitud pasiva en lo referente a la formación de su patrimonio, lo que derivaba en una escasa integración del mismo, baja rentabilidad y dificultades en la explotación (López Martínez, 1995, p. 453). A ello han contribuido las aportaciones de historiadores laicos que han analizado múltiples aspectos de la vida conventual desde prácticamente todos los ángulos: el componente social, su imbricación con los grandes linajes y las élites, el ejercicio de poder, la devoción, la acción social o la perspectiva de género y, más recientemente, la sororidad (Sánchez Lora, 1988; Reder, 2000; Martínez Ruiz, 2004; Atienza, 2008, 2012a, 2012b, 2018, 2019; Viforcos y Loreto, 2007; Gómez Navarro, 2011). Sin embargo, los estudios que abordan aspectos económicos ofrecen mayor dispersión e inconsistencia. A finales de la década de 1980 y durante 1990, se publicaron excelentes trabajos que analizaban las economías conventuales desde el ámbito de la Historia Económica, así como numerosos estudios de caso que constataron la condición de terratenientes de algunas órdenes y el gran peso que en todos ellos alcanzaron los réditos de censos, juros o alquileres urbanos, pero sin ahondar en su evolución en el largo plazo u ofrecer una perspectiva comparada (Llopis, 1980; Atienza, 1988, 1989; López Martínez, 1992a, 1992b, 1995, 1997; Rey Castelao, 1993; Burgo López, 1993; Soriano, 1994, 2000). Tras un periodo de atonía, los estudios del clero se reactivaron con fuerza y, con ellos, los del mundo conventual, aunque desde una perspectiva social, cultural o de género. El enfoque económico quedó como un tema subsidiario y desprovisto, la mayor parte de las veces, de un aparato conceptual o analítico apropiado. No obstante, el tema del patrimonio, las rentas y su gestión volvió a revitalizarse bajo la coordinación de Fiorenzo Landi, quien editó los trabajos presentados en el marco del World Economic History Congress en su doceava y treceava edición, celebradas respectivamente en Madrid 1998 y Buenos Aires 2002, 
(Landi, 1998 y 2004). Más recientemente se ha abordado este tema en el II Congreso Internacional SEHA-REPORT, celebrado en 2018 en la ciudad de Santiago de Compostela, en una sesión coordinada por Pegerto Saavedra y Pablo Luna, en la que se presentó una versión preliminar de este trabajo.

La variedad de perspectivas y la diversidad de formas de abordar las economías conventuales femeninas han dificultado enormemente la labor de realizar una síntesis global que señale los puntos en común sin olvidar la diversidad (Rey, 2009; Atienza, 2010; Gómez Navarro, 2007, 2011). Atienza señalaba la necesidad de diferenciar entre la vida económica de los conventos y la economía particular de las monjas, pues, aunque ambas se entrecruzan, también tienen un recorrido independiente (Atienza, 2010, pp. 250-251). En este sentido, es importante avanzar en el conocimiento de la gestión de los conventos, en el día a día, poniendo el foco en sus verdaderas protagonistas, las monjas. Los equipos de gobierno de los conventos - prioras, comendadoras, vicarias, clavarias, depositarias...- debían tomar a diario decisiones económicas para solventar problemas derivados de la falta de liquidez para hacer frente a los gastos diarios y que no podían esperar a la autorización o el consejo de responsables masculinos. Y lo hacían con criterios que hoy consideraríamos de rentabilidad económica, puesto que de otra forma peligraba su modo de vida y la viabilidad del convento. Solo así se explica que tantos y tantos de ellos subsistieran, casi siempre con escasos medios.

Este trabajo pone el foco, precisamente, en las estrategias de formación, gestión y consolidación patrimonial en el muy largo plazo y desde una perspectiva comparada de dos comunidades femeninas apenas separadas un centenar de kilómetros por las estribaciones meridionales de la cordillera Cantábrica, con marcos jurídicos y económicos dispares. Al sur, en la comarca burgalesa de las Merindades, el monasterio de Santa Clara de Medina de Pomar, propietario de un extenso patrimonio de carácter señorial; al norte, el convento mercedario de Nuestra Señora de la Merced de Markina (Bizkaia), fundado con escasa renta y ninguna propiedad a su nombre. El estudio se realiza a partir de las contabilidades de ambas instituciones, en un lapso de tiempo que abarca desde sus respectivas fundaciones hasta 1800, completadas con los contratos de compra-venta, donaciones, permutas, infurciones, arrendamientos, censos y juros contenidos en sus propios archivos ${ }^{1}$. A pesar de tratarse de un estudio comparado de dos casas concretas, ambas son altamente representativas de la dualidad económica, social y fundacional de la mayoría de los conventos españoles en la Edad Moderna. En los dos contextos, las monjas mostraron una gran capaci-

En el caso de Medina de Pomar se ha utilizado la detallada descripción documental que ofrece el catálogo del archivo del monasterio (Ayerbe, 2000). Este incluye los elementos fundamentales de cualquier contrato por lo que se ha utilizado como base documental para su tratamiento estadístico, dado el ingente volumen de la documentación original. 
dad de adaptación y una gestión utilitarista de los recursos en aras de garantizar la perdurabilidad del proyecto común. Y era el equipo de gobierno económico, con la priora a la cabeza, el que hizo posible esta flexibilidad para afrontar las variaciones coyunturales, sin menoscabo de la autoridad masculina que adoptaría decisiones de mayor calado que afectaban a toda la Orden.

\section{Monasterio de origen medieval, Santa Clara de Medina de Pomar}

Santa Clara fue el prototipo de convento vinculado a una gran casa nobiliaria con un papel esencial en la consolidación del poder de los Velasco (Domínguez Ortiz, 1973, p. 77). A diferencia de otras familias nobiliarias, que no ejercieron su patronato sobre una orden concreta, los Velasco hicieron de su apoyo a la reforma villacreciana un rasgo distintivo e identitario de la casa ${ }^{2}$. Así, la fundación de conventos no solo era una muestra inequívoca de apoyo a los movimientos espirituales reformados, sino que también era un medio de propaganda que pretendía testimoniar el poder y la riqueza del linaje, prolongar su memoria y legitimarlo asociándolo al prestigio de la orden (Paulino, 2013, p. 428).

En el contexto de la guerra de bandos, el apoyo de una orden religiosa otorgaba ciertas ventajas diplomáticas frente a los contrincantes ${ }^{3}$. La fundación de conventos vinculados por razón de fundación y patronato con el linaje contribuía a reforzar los derechos territoriales disputados por cada bandería y a consolidar su presencia a través de donaciones de señoríos, tierras y vasallos ${ }^{4}$. Los Velasco reforzaron su posición en la villa de Medina de Pomar con la fundación, a comienzos del siglo XIV, de sendos monasterios franciscanos 5 . Esta villa era el centro neurálgico de sus dominios que se extendían desde el valle de Mena hasta Orduña por el este y desde Medina de Pomar

Solo en tiempo de Pedro Fernández de Velasco, «El Buen Conde de Haro», se fundaron 12 instituciones relacionadas con los franciscanos (García Sáenz de Baranda, 1917, pp. 104-105). Durante el siglo XV en la provincia franciscana de Burgos se produjo un fuerte conflicto entre la conventualidad (liderada por Pedro de Santoyo) y la observancia defendida por Pedro Villacreces. Sobre este tema véase Muñoz, 2015.

3 «E, tratadas treguas por los frayes de Sant Francisco, fueronse cada uno a sus tierras, e Lope García quedóse en La Cerca, e fueron sueltos todos los presos», Lope García de Salazar, Historia de las Bienandanzas e fortunas, p. 235 (cit. López Martínez y González Terán, 2004, p. 17).

$4 \quad$ Esta práctica fue habitual entre las grandes familias nobiliarias. Los Velasco, los Manrique y los Enríquez fundaron conventos franciscanos para asegurar sus territorios. Otros linajes menores siguieron su ejemplo contribuyendo a la difusión de la orden por Castilla (Beceiro, 2014, p. 321). Otros, como los Ayala, se apoyaron en los dominicos con el mismo propósito (Paz Moro, 2017, p. 105).

Se desconoce la fecha de fundación del convento de San Francisco de Medina de Pomar, aunque se menciona en una donación realizada por Fernando IV en 1306 de 200 maravedís con obligación de celebrar en su iglesia unas misas (Ruiz de Loizaga, 2007, p. 8). En 1313, Sancho Sánchez de Velasco y Sancha García Carrillo, fundaron Santa Clara reforzando su presencia en la villa. 
hasta Aguilar de Campoo por el oeste; todos ellos de un alto valor estratégico, ya que garantizaban el control de las comunicaciones entre Castilla y los puertos cantábricos. Al otro lado de la cordillera sus rivales, los García de Salazar, dominaban las Encartaciones vizcaínas, zona igualmente valiosa por las mismas razones.

Si el apoyo de los frailes era esencial en el tablero político, las monjas no serían menos en el proceso de consolidación territorial y fortalecimiento de los lazos clientelares. Santa Clara acogió a hijas, hermanas y nietas de los Velasco, y las de su clientela, que profesaron en el monasterio para garantizar el control de una parte del patrimonio. Los cargos de abadesa y depositaria se mantuvieron en el ámbito familiar desde que Pedro Fernández de Velasco, I Conde de Haro, excluyera de la sucesión del mayorazgo a su descendencia por vía femenina «porque luego siguen la dignidad, nombre y condición del padre y se perdería el apellido Velasco» (López Martínez y González Terán, 2004, p. 141). Sin embargo, como abadesas ostentaban la titularidad de varios señoríos, vasallos y tierras, e incluso se les permitió testar tras la preceptiva bula papal (López Martínez y González Terán, 2004, p. 52). Desde el monasterio gestionaron y ampliaron parte del patrimonio familiar, contribuyendo a generar recursos de importancia y consolidar así la expansión y legitimación de su poder (Atienza, 2008, pp. 191-193; Jular, 2001). Pero, además, la institución cumplió otra función fundamental, la de guardar y educar a niñas y jóvenes casaderas que esperaban, tuteladas por tías y hermanas, a que se concertase un matrimonio conveniente. Una vez consolidadas las alianzas políticas y garantizada la reproducción del linaje, muchas volvían al claustro tomando los hábitos, o simplemente como huéspedes permanentes, acompañadas de algunas criadas a su servicio ${ }^{6}$.

\section{a) Formación del patrimonio de Santa Clara}

Si bien las constituciones iniciales, dadas por Clara de Asís y aprobadas por Inocencio IV en 1253, propugnaban la «altísima pobreza» prohibiendo terminantemente las posesiones y rentas ${ }^{7}$, lo cierto es que este precepto se fue modificando con

En la documentación aparecen como monjas en el monasterio varias viudas Velasco y pertenecientes a familias clientelares. Entre estas se encuentran la fundadora Sancha García Carrillo, su hija Elvira Sánchez Carrillo y su nieta María Sarmiento (madre de Juan Fernández de Velasco); Beatriz de Manrique (viuda del I Conde de Haro), su hija Leonor de Velasco Manrique (viuda del príncipe de Viana y que ostentó el cargo de abadesa), y sus sobrinas Francisca de Velasco Enríquez (viuda de Diego López de Zúñiga) y Beatriz de Velasco y Mendoza (viuda de García Fernández Manrique). La costumbre de tomar los hábitos al enviudar desapareció en el siglo XVI, probablemente como consecuencia de la reforma del cardenal Cisneros.

«Assi sean obligadas las abadesas que en el Oficio me sucedieren y todas las Hermanas hasta el fin, guardar inviolablemente, de no recibir, ni tener possesion o propiedad por sí, ni por interpuesta persona, u otra cosa alguna que con razón se pueda llamar propiedad, sino quanto fuere necesario para la honestidad, y concierto del Monasterio, podrán tener un poco de tierra, la qual no se labre o cave sino para huerta necessaria para las hermanas» (Constituciones 1662, primera regla, cap. 6, pp. 6-7). 
el tiempo para adecuarse al modo de reproducción económica de la clase feudal. Tan solo diez años más tarde, Urbano IV sancionaría unas nuevas constituciones en las que se permitía «recibir y tener en común renta y posesiones y retenerlas libremente» (Lanzagorta, 2002, p. 34). Es decir, se entendía que la pobreza debía ser personal, pero nada impedía disfrutar de bienes comunitarios que garantizaran la supervivencia del convento y, por lo tanto, adoptar un papel relevante en la consolidación del patrimonio de sus respectivas familias.

La fundación inicial estaba dotada con 300 almudes de pan, mitad trigo y mitad cebada, 700 cántaras de vino, 7 vacas, 200 ovejas y 1.000 maravedís anuales para vestuario procedentes de los bienes de Sancho Sánchez de Velasco y Sancha García Carrillo, sus promotores. Todo ello permitía la manutención de «24 monjas de velo prieto», pero era insuficiente para la construcción del edificio monasterial. Por ello, Sancha Carrillo solicitó la ayuda de Juan XXII quien, en 1318, concedió indulgencias a todos aquellos fieles que «visitando la iglesia colaborasen en la construcción del monasterio con sus limosnas» (Ruiz de Loizaga, 2007, p. 11). El rápido crecimiento del convento obligó a una temprana redotación, de manera que se pudiera mantener holgadamente a 50 monjas. Para ello los Velasco les cedieron unas aceñas, un parral, las ferrerías de Soba y las eras de sal de Rosío, todo lo cual rentaba anualmente 6.600 maravedís. Además, les asignaron 2.200 maravedís anuales y el suministro regular de cera, aceite y otros productos de consumo diario (López Martínez y González Terán, 2004, pp. 24-26). La ratificación y respaldo de Roma a esta fundación llegaría en 1354 a través de sendas bulas en las que concedía al monasterio una amplia autonomía de gestión, al poder intervenir en la designación de visitadores y confesores e impedir a los superiores de la Orden el traslado de sus moradoras a otros conventos sin su consentimiento previo (Ruiz de Loizaga, 2007, p. 11).

El apoyo papal consolidó al monasterio como un referente aristocrático abriendo la posibilidad de exigir abultadas dotes a las aspirantes y, por consiguiente, a un incremento del patrimonio por esta vía. Tanto Pedro Fernández de Velasco como su hermano Hernando de Velasco Solier dotaron a sus hijas con la titularidad de señoríos, vasallos y jurisdicciones que, como se ha explicado anteriormente, fueron transmitidos a las mujeres de la familia tras la perceptiva bula papal. Así, desde su fundación las Velasco aportaron en concepto de dote el señorío - con jurisdicción civil y criminal, alta y baja, mero y mixto imperio - de los valles de Tudela con sus colaciones, Relloso y el lugar de Cubillos del Rojo. Como derechos anejos a este señorío, ostentaban el patronato de las iglesias parroquiales de Artieta y Berrandúlez con sus diezmos; media cuarta de pan — mitad trigo mitad cebada — de cada solar en concepto de reconocimiento de señorío; cuatro fanegas y cuarta de trigo por oblada en calidad de primicias; también recibían una gallina viva y unos manteles por cada 
vez que se llevaba el cuerpo de un difunto a la iglesia (García Sáenz de Baranda, 1926, pp. 102-106). Además, el monasterio recibió el juro heredad de la Merindad de Castilla la Vieja, que había sido cedido por el rey a Pedro Fernández de Velasco en 1379, así como el de «la villa de Salinas de Añana con todas sus aldeas, términos y moradores y con todas sus rentas, más 20.000 maravedís anuales de las rentas de la sal» que Leonor Enríquez, hija del bastardo de Enrique II Fabrique Enríquez, había recibido de su abuelo. Estas salinas vendrían a sumarse a las que ya poseía el convento en Rosío y otros lugares en Asturias, Zamora o Granada ${ }^{8}$. Por tanto, en esta primera etapa, los bienes del monasterio procedían de dotes, donaciones y privilegios que incluían todo tipo de rentas de carácter feudal — señoríos, vasallos, jurisdicciones y pechos y tributos - propiedad de las Velasco, aunque el usufructo recayera sobre el conjunto del monasterio.

Hasta aquí, el comportamiento económico de las monjas en nada difiere de ese papel pasivo que apuntábamos al principio, en el sentido de que el monasterio aparece como mero receptor de estos bienes. Sin embargo, una cuantificación de las escrituras conservadas en el archivo del monasterio ofrece una imagen mucho más activa en la configuración de su patrimonio, ya que las monjas que componen su equipo económico - priora, vicaria y depositarias - intervienen de forma colegiada en contratos de compra-venta, permutas y retrocesiones. Estas operaciones constituyen un ejercicio de administración económica en el que prima la búsqueda de una mejor renta situacional de sus propiedades y una mayor diversidad de las explotaciones. Es precisamente esta intervención directa en la gestión de su patrimonio la que viene a desmentir el carácter exclusivamente rentista de los cenobios femeninos. Estos combinarán estrategias de inversión adecuadas a cada coyuntura, no con la finalidad de obtener un beneficio, sino con la de preservar la percepción de una renta estable en el largo plazo.

Según la documentación que consta en el catálogo documental de Santa Clara (Tabla 1), las compras de inmuebles - especialmente solares y tierras de pan llevar, aunque también aparecen algunos parrales, aceñas y molinos - se intensificaron entre la segunda mitad del siglo XIV y la primera del XV, aprovechando con toda probabilidad la oportunidad que brindó la crisis bajo medieval de hacerse con solares y heredades vacías - más del $20 \%$ de los contratos de compra venta del monasterio tiene como origen una herencia no deseada, o imposible de mantener si la que vende es la viuda-. Estas operaciones se realizaron con el dinero percibido por la renun-

Archivo del Monasterio de Santa Clara de Medina de Pomar (en adelante AMMP), cod. 3.1., sigs. 01.03 y 01.04. Felipe II se apropiaría de las salinas pertenecientes a los Velasco y a Santa Clara a la muerte del Condestable Pedro Fernández de Velasco, dejando a las monjas una renta anual de 58 fanegas de sal. 
cia de las legítimas y fueron hechas a título particular tanto por la abadesa como por otras monjas pertenecientes a familias clientelares de los Velasco.

Tabla 1. Número de contratos suscritos por el Monasterio de Santa Clara de Medina de Pomar

\begin{tabular}{|c|c|c|c|c|}
\hline & COMPRAS & DONACION & PERMUTAS & VENTAS \\
\hline$<1350$ & 4 & - & - & - \\
\hline $1350-1399$ & 20 & - & 3 & - \\
\hline $1400-1449$ & 18 & - & 13 & 2 \\
\hline $1450-1499$ & 10 & - & 4 & 2 \\
\hline $1500-1549$ & 19 & 7 & - & - \\
\hline $1550-1599$ & 1 & 2 & 2 & 1 \\
\hline $1600-1649$ & 4 & 1 & 2 & - \\
\hline $1650-1699$ & 29 & 5 & 2 & 3 \\
\hline $1700-1749$ & 16 & - & 7 & 1 \\
\hline $1750-1799$ & 11 & - & & 2 \\
\hline
\end{tabular}

Fuente: Elaboración propia sobre datos contenidos en Ayerbe, 2000.

A falta de un análisis más preciso, en esta etapa se puede observar un patrón común en la estrategia de expansión territorial del monasterio: las tierras adquiridas se encontraban en localidades de behetría o de señorío compartido9. Es decir, los Velasco utilizarían a las monjas para establecer relaciones contractuales con los vecinos de estos lugares, intensificando su presencia en un territorio cuyo control no tenían garantizado. El prestigio del monasterio y su proyección social podía decantar, en un momento determinado, el sentido de la elección en favor de un miembro del linaje.

A partir de 1450, las compras de terrenos decayeron en favor de las permutas. En estas operaciones se observa una actitud activa por parte de las monjas al racionalizar las características de un patrimonio heredado, tal y como se desprende de una bula papal en la que se les concede «la facultad de poder vender y permutar los bienes muebles y estables que se hallan con alguna distancia de dicho convento» ${ }^{10}$. El monasterio cambió casas, solares edificables, molinos o aceñas de titularidad compartida por de tierras de pan llevar.

A pesar del ingente patrimonio acumulado, las monjas pasaron por momentos de apuro económico, acuciadas por la magnitud de los gastos y, probablemente, por una mala administración. Por lo que se desprende de los contratos de venta, en 1411

\footnotetext{
9 Las Behetrías eran localidades cuyos vecinos, como dueños absolutos del lugar, podían elegir señor a quien quisiesen. El libro Becerro de las Behetrías de Castilla da cuenta de la situación jurisdiccional en 1351 de las localidades al norte del Duero repartidas en 15 merindades (Becerro, 1886).

10 AMMP, cod. 1.2., cajón O, legajo 11, cuadro. 11. La copia que se conserva es una ratificación de finales del siglo xv, pero ignoramos la fecha exacta de emisión del privilegio.
} 
tuvieron que hacer frente a la reparación de las dependencias del monasterio con la venta de bienes y vasallos: los de Villarías y Piña (en tierra de Campos, obispado de Palencia) «por la dificultad de su administración y gran necesidad de reparación en dormitorio y clausura que tenía el monasterio» ${ }^{11}$; y, años más tarde en 1488, de los de Hoz de Arreba y otras heredades lejanas «para hacer frente al gasto de reparación del monasterio en especial la enfermería que está para caer» ${ }^{12}$.

\section{b) La adecuación a los tiempos modernos: preferencia por los bienes de capital}

Con la llegada de la modernidad el monasterio hubo de adaptarse a los cambios de estrategia de las familias en la dotación de sus mujeres. Los señoríos y derechos jurisdiccionales desaparecieron de dotes y legítimas para ser sustituidos por censos y juros. Si bien es verdad que durante los siglos XVI y XVII el monasterio recibió como donación varias tierras y heredades (ver tabla 1), no es menos cierto que fueron excepciones en un contexto de monetización de las economías conventuales. La reducción de operaciones de compra-venta de inmuebles en estos años confirma esta preferencia por los bienes de capital, cuyos réditos complementaran los ingresos procedentes de la renta de la tierra, que también se irá desprendiendo de su carácter feudal para adecuarse a los nuevos tiempos. En este cambio de estrategia debieron confluir varios factores, pero sin duda la percepción de un interés fijo, garantizado por la Corona y sin gastos de gestión, resultaba más atractivo que la explotación de unas tierras cuyos rendimientos presentaban una clara tendencia descendente (Gráfico 1) $)^{13}$.

Hasta la segunda mitad del siglo XVI, el monasterio explotó sus tierras mediante infurciones y enfiteusis, aunque para entonces habían perdido su carácter señorial convirtiéndose de facto en arrendamientos perpetuos y a largo plazo, respectivamente. La coyuntura expansiva y el alza de los precios de la segunda mitad del siglo XVI provocaron un fuerte incremento en la renta media que se percibía en este tipo de contratos y propiciaron la firma de otros a corto plazo, generalmente de 9 años y pagaderos en especie, con una rentabilidad muy superior a la que presentaban las enfiteusis e infurciones. A finales del siglo XVI, con el inicio de la crisis agraria se observa un proceso de convergencia a la baja en la renta percibida en ambas figuras contractuales, descenso que se prolonga hasta finales del siglo XVII en el caso de los

AMMP, cod 3.1., perg. 121.

AMMP, cod 3.1., perg. 131.

Evidentemente, con los datos que nos ofrece el catálogo de Ayerbe (2000) no se puede realizar un análisis exhaustivo de la evolución de la renta de la tierra, ya que no tenemos el dato de la extensión o calidad de las mismas, pero sí que nos permite trazar una tendencia de la misma ya que las rentas se perciben, a lo largo de todo el periodo estudiado, en especie, pan mediado de trigo y cebada a partes iguales, y, en algunos casos puntuales, 1 o 2 gallinas, rara vez en dinero. 
Gráfico 1. Renta de la tierra en especie según tipo de contrato en Santa Clara de Medina de Pomar, 1320-1799 (promedios anuales en periodos de 25 años)

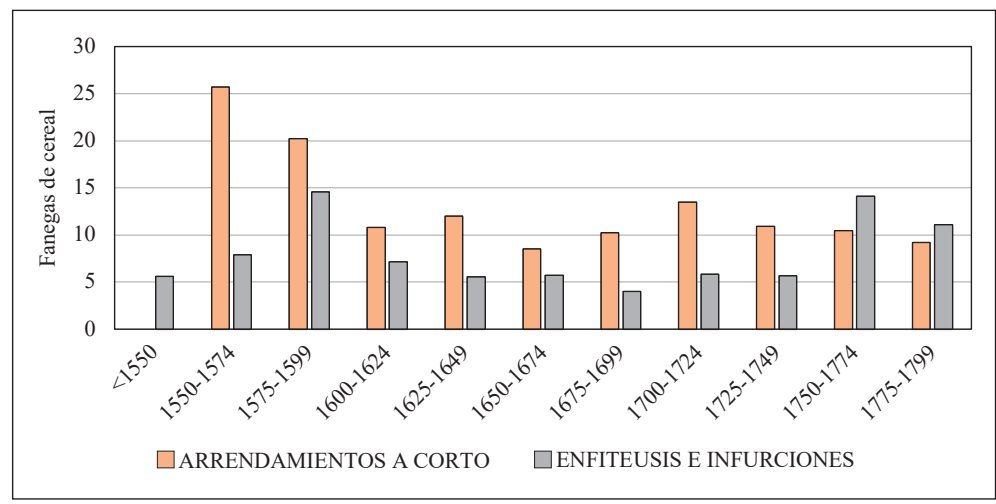

Fuente: Elaboración propia sobre Ayerbe, 2000.

arrendamientos y hasta una centuria después para las enfiteusis. La recuperación de los contratos a corto plazo estuvo acompañada de una reducción de la duración media de los mismos de 9 a 7 años, aunque no volverán a registrar los niveles alcanzados en las centurias precedentes.

Por otra parte, durante el siglo XVI las familias comenzaron a mostrar una preferencia por los bienes de capital para dotar a sus mujeres o compensarlas por la renuncia a sus legítimas. El incremento de las necesidades financieras de la Corona, con la emisión de juros situados sobre alcabalas, diezmos de la mar o almojarifazgos, abrió la puerta a una monetización de las relaciones contractuales entre la rama principal de la familia, que seguía ostentando la titularidad de los bienes inmuebles, y las ramas secundarias, que participarían de la rentabilidad de la expansión económica a través de la percepción de intereses anuales elevados y transmisibles entre generaciones por ser los juros perpetuos o de heredad.

El gráfico 2 da buena cuenta de este cambio de tendencia, que viene a coincidir con una reducción significativa de los contratos de compra-venta, donación o permuta de bienes inmuebles ${ }^{14}$. Durante el siglo XV y especialmente en la primera mitad del XVI, el monasterio recibió por donación directa de la Corona, o indirecta a través del Condestable, numerosos juros heredad con situados en las alcabalas de territorios controlados por los Velasco o sus clientelas: Merindad de la Rioja, Valle de Arreba, Burgos, Belloso, Soria y varias localidades menores de la Merindad de

Se han dejado fuera del análisis aquellas escrituras de reclamación de intereses y venta de juros en poder del monasterio. 


\section{Gráfico 2. Escrituras de bienes de capital suscritas por el Monasterio de Santa Clara de Medina de Pomar (1520-1819)}

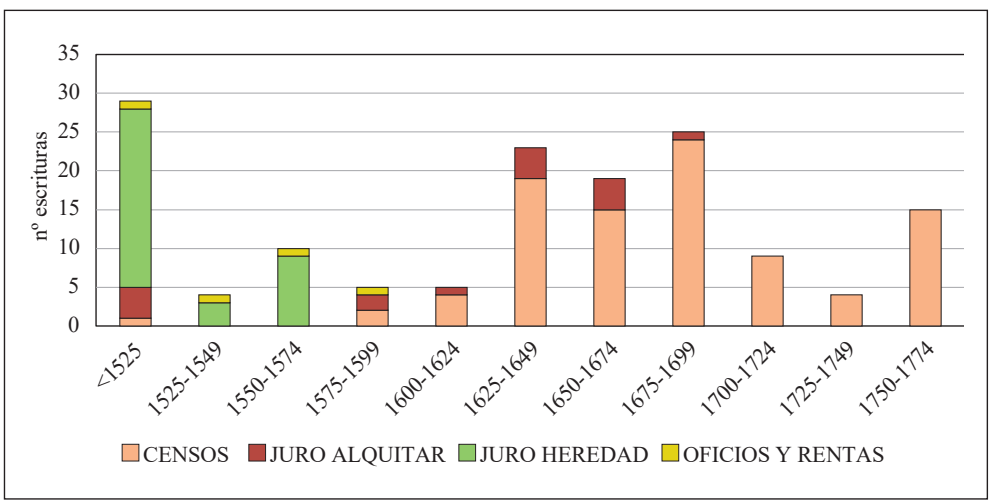

Fuente: Elaboración propia sobre Ayerbe, 2000.

Castilla La Vieja ${ }^{15}$. Estamos en un momento de transición en el que se participa en la expansión económica a través de rentas con un alto interés, de carácter perpetuo y transmisible. Fueron estas características lo que las hizo muy atractivas para la clase feudal, ya que tenían todas las ventajas de la renta de la tierra, pero con una mayor rentabilidad que aquella — entre 10.000 y 14.000 al millar-. Además, se constituyeron como instrumentos con los que poder hacer frente a donaciones, fundación de capellanías, memorias de misas y dotes sin alterar el patrimonio familiar. Esta debió ser una forma recurrente de compensación de la Corona a sus vasallos más fieles, ya que hasta 1560 la mayor parte de los juros en circulación eran perpetuos y estaban en manos del clero (López Martínez, 1992a: 436).

La progresiva liberalización de la prohibición de compra de juros al quitar por parte de la Iglesia, especialmente en el reinado de Felipe II, permitió adquirir títulos a todo aquel que lo deseara y venderlos a instituciones eclesiásticas, en principio solo por vía merced, nunca de compra (Toboso, 1987, pp. 57-58 y 189). A partir del último tercio del siglo XVI, Santa Clara recibió juros alquitar de manera esporádica, a veces en concepto de dote y otras como donación, aunque debido a la inestabilidad en el cobro de sus réditos el monasterio prefirió las dotaciones en censos consignativos.

15 Cabe destacar una donación realizada al monasterio por el Condestable de Castilla de las rentas de la villa de Balmaseda o los diezmos de la mar en 1511 (AMMP, cod. 3.4, sig 36.26-27) o la de la manda testamentaria de la reina Juana por la que cedía al monasterio de santa Clara los juros perpetuos sobre las alcabalas de Villarán, Trespadierna, Villapanillo, Miñón, Bocos, Frexno, Tormé y Villanueva, todas ellas localidades de la Merindad de Castilla la Vieja (AMMP, cod. 3.4, sig, 37.09). 
Durante el siglo XVII, la dificultad de la cobranza de los intereses de los juros queda reflejada en el incremento de las reclamaciones y los pleitos por impago de los mismos, que a veces concluían con la concesión del permiso real para su venta. La pérdida de rentabilidad de la deuda pública fue aprovechada por algunas familias para «deshacerse» de estos activos al utilizarlos como bienes dotales de fundaciones piadosas, compensación de herencias o dotación de monjas (Domínguez Ortiz, 1960; Toboso Sánchez, 1987; y, López Martínez, 1992a). La ventaja económica era evidente. Por una parte, se negociaron de acuerdo con su valor nominal, en ningún caso con el real, por lo que se produjo un evidente abaratamiento de las dotes. Por otra, estos bienes, en continua depreciación, se revalorizaban al beneficiarse de las ventajas fiscales aplicadas los bienes eclesiásticos. Por último, las familias tuvieron la oportunidad de financiar los servicios religiosos de fundaciones y obras pías sin comprometer otras rentas de mayor estabilidad. Esto generó graves problemas para aquellos conventos que los habían admitido como pago de las dotes o como instrumento de capitalización de fundaciones gravadas con misas o limosnas, cuyo precio real excedía el valor de su renta ${ }^{16}$. El monasterio de Medina no fue ajeno a esta tendencia ya que, en el último tercio del XVII, había admitido como bienes dotales juros alquitar situados sobre las alcabalas y rentas de localidades dentro de su área de influencia, lo que sin duda debió repercutir negativamente en el estado de sus cuentas ${ }^{17}$.

El gráfico 2 también muestra la prevalencia de los censos a partir de 1625, aunque a diferencia de otros conventos, el de Santa Clara no jugó un papel destacado como oferente de capitales. El rico patrimonio inmobiliario que había ido acumulando desde su fundación, así como la cobranza de señoríos, rentas y oficios, contribuyó a que la labor crediticia fuese puntual y tuviera como finalidad principal proveer de fondos a la rama principal de la familia en momentos de dificultad. Por ejemplo, en 1632 Bernardino Velasco y Tobar hipotecó las rentas y alcabalas de la Villa de Medina y las de Frías a cambio de censos por valor de 1.400 ducados a favor del monasterio. Salvo estas contadas excepciones, el resto de los títulos procede del pago de dotes, donaciones testamentarias o fundaciones piadosas. Desde el siglo XVIII, se observa

16 Este fenómeno debió ser frecuente en el último tercio del siglo XVII, ya que también lo encontramos en muchos de los conventos del País Vasco. Por ejemplo, en Santa Isabel de Gordejuela, el visitador advierte a las prioras sobre esta práctica, aleccionándolas sobre el modo de proceder. Archivo Histórico Eclesiástico de Bizkaia - Bizkaiko Elizaren Histori Artxiboa (en adelante AHEB-BEHA), sig. 4035/003/00.

17 Los juros que recibe el convento en el último tercio del siglo XVII en concepto de dote estaban situados sobre las alcabalas de las 7 merindades de Castilla La Vieja, las del partido de Cervera y las salinas de Castilla la Vieja. Como compensación de legítimas se adquieren las rentas de las Salinas de la Ciudad de Granada, los millones de la ciudad de Burgos y las alcabalas de Torrecilla de Cameros (AMMP, cod. 3.4., sig 37.29; 27.34-35; 38.12; 38.20 y 39.04) 
un drástico descenso de la inversión en deuda privada, aunque el promedio del capital prestado en cada escritura fue muy superior al de épocas anteriores, teniendo como principales destinatarios a los concejos necesitados de fondos para acometer obra pública o paliar la deuda municipal ${ }^{18}$. Esta reorientación en la cesión de capitales hacia concejos y alta aristocracia fue común a la mayoría de los conventos de la península y duró hasta la última década del siglo XVIII, cuando se recuperó el mercado del crédito entre particulares debido a la crisis finisecular (Atienza, 1989, pp. 8-9).

La pérdida de cabimiento de los juros y la evidente reducción de los censos, desde el arreglo monetario de 1680, llevó a todos los conventos de la península a replantearse la composición de sus rentas apostando por una gestión más flexible y versátil de su patrimonio inmobiliario. Como hemos visto en la tabla 1, Santa Clara de Medina de Pomar no se sustrajo a esta tendencia, reactivando las compras de inmuebles entre el último tercio del siglo XVII y el primero del XVIII. Este proceso discurrió paralelo a un aumento de la renta que se exigía por su explotación, aunque sin alcanzar los niveles del Quinientos. La crisis finisecular reactivó los contratos a perpetuidad con una renta media que, por primera vez, superaba la de los arrendamientos a corto. Sin duda, la supresión de la tasa del trigo y el alza de los precios agrícolas estimularon el incremento de la renta en especie y la preferencia de las monjas por contratos duraderos que les garantizaran la continuidad en la explotación, especialmente en el inestable y convulso fin de siglo.

\section{Convento reformado: Nuestra Señora de la Merced de Markina}

Al otro lado de la cordillera, en la cornisa Cantábrica, la realidad conventual era bien diferente. Allí, y muy especialmente en Bizkaia y Gipuzkoa, los conventos tuvieron su origen en beaterios que formaban parte del entramado eclesiástico dominado por los patronos laicos ${ }^{19}$. Durante los siglos XV y XVI, los miembros de líneas secundarias de las principales familias y de las oligarquías urbanas aprovecharon la fuerte demanda de vida religiosa provocada por la reforma observante para fundar un beaterio. Con ello, pretendían emular el comportamiento de los grandes linajes nobiliarios en sus estrategias de reproducción social, preeminencia y honor. En pri-

18 El monasterio prestó al concejo de Moneo de 22.000 reales de vellón para construir un puente sobre el río.

19 El patronato laical en el País Vasco se remonta a la época anterior a la reforma Gregoriana y se institucionalizó con el reconocimiento real del Fuero Nuevo en 1526, lo que explica su pervivencia hasta la abolición de este. La posesión de una iglesia (por fundación o donación real) daba derecho a la integridad de los diezmos, la presentación de clérigos y seroras (sacristanas que cuidaban del mantenimiento del templo parroquial o de las ermitas dependientes de la misma), el enterramiento preferente y la ostentación de símbolos nobiliarios en la Iglesia. 
mer lugar, la fundación de un beaterio garantizaba a la descendencia femenina la entrada en la vida religiosa, ya que era muy difícil ingresar en un monasterio, tanto por la cuantía y características de las dotes exigidas, como por la obligatoriedad de pertenecer a alguna de las redes clientelares que dominaban los grandes conventos, tal y como se ha visto en el caso de Santa Clara. Los vínculos de sangre fueron siempre los criterios que presidieron las escrituras fundacionales en las que el titular se reservaba el derecho a disponer libremente de varias plazas destinadas a mujeres de la familia o relacionadas con la misma. En segundo lugar, constituía una magnífica oportunidad para ostentar los símbolos de preeminencia derivados del patronato o engrandecerlos. Así, en el mundo rural los beaterios, la mayoría de las veces situados junto a la parroquia, compitieron con ésta como escenario de representación de honor y preeminencia de las familias que los sustentaban; mientras que, en las ciudades contribuyeron a ennoblecer a las principales fortunas procedentes del comercio. Por último, ofrecían la posibilidad de perpetuar en manos de la familia fundadora el usufructo de aquellos bienes que no estaban comprometidos en el mayorazgo principal. La cesión de una parte de su patrimonio fue la piedra angular de la relación que se establecía entre el patrón y su fundación, que además quedaba amparada por el Fuero, especialmente si habían contribuido a edificar el templo. De hecho, las beatas quedaban integradas en la estructura del patronato en absoluta dependencia del titular del mismo, al igual que lo estaban los beneficiados y seroras, ambos designados y pagados por el propietario de la iglesia.

La mayoría de los beaterios se erigieron con dotaciones económicas muy modestas o con severas restricciones en cuanto al número de personas que podían albergar, el máximo de renta al que podían aspirar o la dote que debían exigir. El decreto tridentino de obligatoriedad de la clausura para todas las comunidades religiosas femeninas alteró profundamente el statu quo de estas fundaciones. Los patrones debían garantizar su supervivencia económica y someterse a las directrices de la Orden bajo la que habían profesado, ya que con el decreto se incorporaban de pleno en la estructura jerárquica de cada una de ellas. De esta manera, el patronato quedaría circunscrito a los símbolos de preminencia — enterramiento preferente y el compromiso por parte del convento de llevar a cabo las memorias de misas y aniversarios correspondientes - pero sin ningún derecho sobre las decisiones económicas u organizativas de la comunidad. No todos los patrones aceptaron esta modificación y en consecuencia muchos dieron por finalizado su compromiso con las comunidades que habían amparado hasta entonces. Algunas desaparecieron, otras tuvieron que buscar otros patrocinadores que aceptaran la nueva situación y otras, como el caso que nos ocupa, iniciaron una vía de gestión independiente de sus recursos. 
a) De beaterio a convento: la ruptura de las relaciones de patronato e inicio de la administración autónoma

El futuro convento de la Merced de Markina fue fundado como beaterio, bajo el nombre de Nuestra Señora de la Piedad, en 1547 por manda testamentaria del señor de la casa de Bidarte, quien compartía el patronato de la parroquia de Santa María de Xemein con otras dos familias ${ }^{20}$. Este derecho compartido le permitía gozar de un tercio de los diezmos, pero no el de enterramiento preferente o nombramiento de clérigos. Las posibilidades económicas de la familia Bidarte eran exiguas y la fundación constituiría un medio por el cual incrementar su capital social y acrecentar su poder económico a través del convento.

La fundación establecía una renta anual de 50 fanegas de trigo, procedentes de unas propiedades que tenían en Álava y que en principio debían ser suficientes, junto con el producto de una pequeña porción de tierra, para satisfacer las necesidades de 10 monjas. El codicilo testamentario también limitaba la renta máxima a 30.000 maravedís anuales y 100 fanegas de trigo, señalando que cualquier incremento de capital se debía invertir en «tierra para huertos y manzanales e mas tierra de 150 pies de castaños, un robledal que se pueda cortar en cada cortadura hasta 100 cargas de carbón para leña ${ }^{21}$. Esta cláusula concreta del testamento es sumamente interesante porque refleja una estrategia de expansión del patrimonio inmueble de la familia fundadora. Como se demostró en el pleito posterior con el patrón, el beaterio solo usufrutuaba los bienes adquiridos con el importe de las dotes y de facto gestionados por los Bidarte que eran quienes tomaban las decisiones económicas. Si el beaterio se trasladaba de lugar o desaparecía, los bienes pasaban a ser propiedad de la familia fundadora. Entre tanto, se aseguraba el control de los mismos a través de su derecho a voto que valía «tanto como el de todas las novicias y religiosas ... de tal manera que no tengan más preeminencia uno que las otras $\rangle^{22}$.

En la década de 1570 las autoridades de la Orden de la Merced, a la que pertenecían las beatas, habían puesto en marcha la reestructuración de sus beaterios para garantizar su viabilidad económica en el marco de la clausura obligatoria. Para ello, habían decretado la supresión de aquellos que estaban alejados de los núcleos principales de población para reagruparlos con un criterio de eficiencia económica que permitiera su supervivencia material. Los conventos de acogida se vieron desborda-

\footnotetext{
20 Xemein era una de las dos parroquias que componen el municipio de Markina-Xemein, y se encontraba extramuros de la villa de Markina, que era la localidad principal.

21 Archivo de las Mercedarias Misioneras de Berriz/España (en adelante ES/AMMB), Fondo de Markina [AM-F.06.00.00] (en adelante [AM]), 0008/002-01: Cédula de fundación del beaterio del convento de Markina. 05-08-1547.

22 ES/AMMB/AM-0008/002-01.
} 
dos al ver duplicado el número de internas, sin que sus rentas se incrementaran en la misma medida puesto que los bienes dotales quedaron en poder de los patrones. En esta reorganización, el beaterio de Xemein se vio obligado a acoger a las compañeras de Ibárruri y Bérriz, lo que implicaba alterar los términos de la fundación en lo que respecta al número máximo de monjas permitido y al destino de las dotes. Se intentó negociar con los Bidarte para cambiar estos dos puntos concretos y adecuar la casa a la nueva legislación, sin éxito. El patrón optó por no pagar la renta en trigo para forzar a las monjas a volver a la situación previa a la reestructuración. Ante esta actitud, las autoridades mercedarias ordenaron que admitieran novicias hasta alcanzar el número de 28 monjas de coro y 4 hermanas legas e invirtieran sus dotes, no en tierras y montes como indicaba la fundación, sino en censos consignativos «por cuanto el dicho Martín de Bidarte en nada cumple con el convento» ${ }^{23}$. Tras años de desencuentros, la ruptura definitiva se produjo en 1621 cuando el convento se trasladó a otra ubicación intramuros de la villa de Markina, cambiando su nombre por el de Nuestra Señora de la Merced y Redempción de Cautivos. El precio que tuvo que pagar a cambio de su independencia económica fue la renuncia a todas las mejoras, enseres, bosques y tierras procedentes de la inversión de dotes en los 73 años que duró el vínculo con la casa Bidarte.

\section{b) Dotes y actividad crediticia}

Desde la ruptura con el patrón, el número de novicias se disparó y con ellas las dotes. Estas fueron invertidas en el mercado de capitales, coincidiendo con una fuerte demanda de crédito agrario. El convento rara vez las admitió en forma de propiedades inmuebles; primero, porque las constituciones de la orden prohibían explícitamente que «las religiosas posean bienes rayces, como propios, aunque sea solo para usufructo» (Constituciones, 1624, cap. XX, pp. 19-22); y, segundo, porque la experiencia de la época de beaterio las prevenía sobre cualquier tipo de cesión de la propiedad, puesto que podían acabar perdiéndola si entraban en litigio con la familia donante. A diferencia de los monasterios de origen medieval, que como hemos visto mantuvieron un importante patrimonio inmobiliario durante la Edad Moderna, en los observantes predominó la preferencia por los censos, al menos hasta el siglo XVIII. En la lógica económica del Antiguo Régimen era la percepción de rentas monetarias procedentes de la propiedad de la tierra (en cualquiera de sus formas) lo que permitía mantener holgadamente un estatus privilegiado. Los censos cumplían con creces esta aspiración, ya que permitían percibir una renta sin tener que hacer frente

ES/AMMB/AM- 0008/002-09. Breve historia del Convento de Marquina escrita por sor Cecilia, organista del Convento sd-sm-1547/16-03-1987. 
a los gastos de explotación o a las variaciones del ingreso propias de épocas de gran inestabilidad económica ${ }^{24}$.

A partir de la década de 1640, la transformación que se estaba produciendo en el campo vizcaíno, al sustituir las viejas pomaradas por campos de maíz, constituyó una oportunidad de negocio inigualable ya que muchos caseríos solicitaban préstamos con un principal inferior a los 100 ducados para hacer frente a las labores de rotura y el acondicionamiento de los campos. Los censos consignativos suscritos con este fin obligaban al caserío y sus pertenecidos, con independencia de la persona física que en ese momento lo representaba. No se trataba necesariamente de bienes vinculados o amayorazgados sino simplemente de una unidad de explotación que se procuraba mantener indivisible, debido a la prevalencia del derecho de primogenitura en la transmisión hereditaria. Para las monjas, los réditos debidos por este concepto eran «rentas», diferenciándolos claramente de aquellos en los que el convento solo adquiría el derecho a exigir los réditos correspondientes al capital y el precio que se pagaba por ellos, aunque estos también estuvieran respaldados por la garantía de un inmueble ${ }^{25}$.

Si la necesidad de capitales permitió ampliar las expectativas de inversión, también dificultó el pago de las dotes y el gasto que originaba el periodo de noviciado - que incluía comida, vestido y costas de sacristía - . Para evitar que la falta de medios constituyese un impedimento para ingresar en el convento se arbitraron una serie de facilidades de pago y soluciones «creativas». Entre 1650 y 1670 fue frecuente aceptar el usufructo temporal de explotaciones ganaderas, bosques, tierras o molinos por lo que durante un breve periodo de treinta años aparecen entre los apuntes de ingreso rentas derivadas de la explotación de estos bienes, sin haber accedido a la propiedad $^{26}$. Sin embargo, lo más frecuente era que las familias cedieran la titularidad de un censo ya constituido en pago de la dote, aunque en este caso se trataba de familias con una posición económica desahogada. Las que procedían de un estrato social más bajo contrajeron con el convento una obligación censal cuyos réditos iban destinados de forma específica a cubrir primero los gastos del noviciado y más tarde a pagar el importe íntegro de la dote. Si la familia conseguía liquidar la deuda, los

24 La equiparación de censos con la renta de la tierra ha sido ampliamente tratada por la historiografía. Cabe señalar la obra seminal de Bartolomé Clavero, 1974.

25 ES/AMMB/AM-0019/002-00: Libro de la Hacienda del Convento de la Merced de Markina, 1619-1728.

26 Así en 1630, Martín Pérez de Abaitua cedió la explotación y crianza de varias cabezas de ganado hasta que fuera satisfecha la deuda que contrajo por la dote y manutención de su hija al ingresar en el convento. O el padre de Ana de Cristo que había entregado a cuenta, para cubrir el gasto de noviciado, 4 quintales de hierro que fueron valorados en 200 reales, cantidad que no cubría la deuda de 4.400 reales que había generado su hija y que le obligó a comprometer parte de la producción de su ferrería hasta reunir el dinero exigido para la profesión definitiva (ES/AMMB/ AM-0011/001-00). 
capitales volvían a imponerse a censo o, si aquella lo deseaba, se seguían pagando los intereses hasta la muerte de la monja, momento en el cual la relación contractual quedaba liquidada y la familia recuperaba el dominio pleno de los mismos.

Las alteraciones monetarias ocasionaron una pérdida de poder adquisitivo de los intereses devengados por los censos consignativos. Eran frecuentes los retrasos en el pago de los réditos por las dificultades campesinas para hacer frente a los mismos, además de comprometer seriamente sus posibilidades de redención. En estos casos, la consigna no fue la ejecución de la hipoteca sino buscar una vía que permitiera conservar la relación contractual sin tener que responsabilizarse de la explotación. La solución adoptada por las monjas fue permitir el pago fraccionado de los réditos vencidos y su aplazamiento más allá de lo que permitía la ley (Ballester, 2005-2006). Esta medida provocó una gran inestabilidad en los ingresos del convento al poner en riesgo la viabilidad del gasto ordinario y obligando a las comendadoras a recurrir a empréstitos, tanto de particulares como de su peculio personal. A partir de 1643, para aminorar los efectos de la devaluación monetaria se comenzó a exigir al menos un tercio de la dote en moneda de plata. Esta se cambiaba por vellón, obteniendo un beneficio del diferencial, que se utilizó para comprar trigo o para imponer los capitales en nuevos censos de pequeña cuantía. Esta estrategia de diversificación del riesgo consiguió minorar el impacto de los impagos ${ }^{27}$. En la segunda mitad del siglo XVII, varios testimonios indirectos recogidos en la contabilidad dan cuenta de un cambio en el tratamiento de las deudas o el retraso en el pago de los réditos. Por una parte, el convento consta como censualista de otras instituciones como consecuencia de haber adquirido bienes concursados de los que había que hacer frente al descubierto correspondiente ${ }^{28}$. Por otra parte, varios de los antiguos deudores aparecen como arrendatarios de las fincas que cubrían la garantía hipotecaria, por lo que cabe suponer que debieron liquidar la deuda con la cesión del inmueble. Por último, entre 1664 y 1675 , vendieron varias propiedades «atento a que les cuesta más los concursos que cada día hacen por la estrechez de los tiempos» ${ }^{29}$.

A pesar de estos tímidos pasos en la adquisición de propiedades, no será hasta la década de 1690 cuando las mercedarias de Markina inicien su expansión inmobiliaria.

27 «Recibiéronse 100 ducados de vellón del premio de 200 ducados de la plata de la dote de Úrsula san Francisco que mandó el maestro provincial se comprase de trigo y estuviese siempre en trigo o en dinero», Markina 1651 (ES/AMMB/AM-000/002-00).

28 Por ejemplo, en 1648 el convento aparece como censualista de la villa de Ondárroa ya que había comprado en concurso de acreedores de los bienes de Martín de Ochoa de Olazábal, haciéndose cargo de la deuda (ES/AMMB/AM-0011/001-00).

29 Entre ellas las caserías de Beitia e Yturrino, una huerta en Mutriku, el Molino de Chiquisalto o las tierras que el convento «tiene en tierra de la Rioxa, assi de viñas como olivares, tierras y casas y censos» (ES/AMMB/AM-000/002-00 y AM-006/001-35). 
Sin duda, el arreglo monetario de 1680 contribuyó decisivamente al abandono de la actividad crediticia como base económica en la mayoría de los conventos españoles y un cambio de estrategia hacia la adquisición de bienes inmuebles, tanto rústicos como urbanos (López Martínez 1992b y 1995; Atienza 1989; Catalán, 2000; Soriano, 1994 y 2000). La estabilización de la moneda de vellón conllevaba además de una deflación, la reducción en los arrendamientos, en el precio de las hipotecas y en los tipos de interés del capital mobiliario, argumentando que «la compra de los frutos de la hipoteca, y la paga de réditos [es] una tácita recompensa del valor de ellos: de donde se infiere que minorado el valor de los frutos se debe minorar el peso de los réditos» (Martínez de Alarcón, 1692, f.,151 vº).

La oposición del clero a esta medida fue contundente y quedó plasmada en el memorial que presentó Gerónimo Martínez de Alarcón, en representación del clero de Castilla, ante Carlos II en 1692. Su argumentación ponía claramente de manifiesto las gravísimas consecuencias que, a su juicio, tendría la medida para el conjunto de la economía. En primer lugar, el mercado de capitales se vería gravemente comprometido, ya que nadie querría prestar dinero por la baja rentabilidad de los intereses y por la dificultad en la cobranza de los mismos. Como consecuencia de esto, los agricultores y propietarios no encontrarían quien les quisiese prestar «para mejorar sus explotaciones, comprar yuntas o pagar criados por lo que la hacienda irá a menos hasta desaparecer». En segundo lugar, se alertaba de que la medida produciría un aumento de bienes espiritualizados, puesto que la mayoría de los acreedores eran eclesiásticos y preferirían ejecutar las hipotecas ya que «a igualdad de renta ha sido y es más estimaba lo raíz por la mayor perpetuidad, respecto a no estar sujeto a los riesgos de concursos de acreedores, de redenciones y baxas de moneda, y otros accidentes». En tercer lugar, el precio de la tierra disminuiría, ya que el acreedor, antes del concurso de acreedores, intentaría vender la propiedad y a pesar de que los bienes «van tasados por un tercio más de lo que valen, con la aminoración de los réditos y la dificultad de encontrar capitales», el precio de venta acabaría siendo bajo. Además, el abaratamiento del precio de la tierra permitiría el acceso a la propiedad de los «sujetos más humildes de la República» por lo que cabía el riesgo de que el orden estamental acabara por invertirse. Por último, ponía de manifiesto las dificultades que la medida acarrearía para mantener la viabilidad económica de los conventos de monjas y de las obras pías dotadas con censos, comprometiendo por tanto su labor asistencial.

Dezir que es pequeño contrapeso la ruina de los Conventos de Monjas, y aniquilación de las obras pías. [...] Los conventos de monjas [...] deben ser cuidados y asistidos, para que por falta de lo temporal, no se aprissione el espíritu con los grillos de las necesidades corporales. Estas son casi universales, con el qual no se compone 
bien el cuiado y beneficiación de otras haziendas, emplean las dotes y capitales en compra de censos, siendo estos de tan poca o ninguna seguridad, experimentan en ellos las más fatales quiebras, con que han llegado a lo último de la miseria, careciendo en algunos del pan y agua necesario [...] Si las rentas conventuales, por su menoscabo, no alcançan a mantener lo material de las casas, por cuya causa está arriesgada en muchas la clausura, como podrán mantener religiosas indotadas? ¿Y si con los réditos que tienen, no pueden sustentarse, como se alimentaran sin ellos? (Martínez de Alarcón, 1692, f., 155vº)

A pesar de los argumentos dados y de que el clero apeló a los servicios y donativos que la Iglesia había cedido al rey para mantenimiento de la Real Hacienda, la reducción de los tipos de interés del 5 al 3 por ciento fue sancionada el 12 de febrero de 1705 por Real Pragmática.

c) Formación y consolidación del patrimonio inmobiliario del convento de Nuestra Señora de la Merced de Markina

Entre 1690 y 1730, la notable disminución de los ingresos ordinarios obligó a las monjas de Markina a reducir el número de novicias y solicitar varias veces el permiso del provincial para utilizar el importe de las dotes y legítimas para hacer frente a la compra de trigo y a los gastos más indispensables de la casa. Durante este periodo, se multiplicaron los concursos de acreedores y, con frecuencia, los bienes concursados no alcanzaron para cubrir la deuda, dadas las condiciones de deterioro en que se encontraban las propiedades. No sabemos si obligadas por las circunstancias o con una estrategia definida, las monjas decidieron apostar por invertir en la mejora del patrimonio raíz para poderlo vender o arrendar más fácilmente:

Hemos puesto cedulas de venta para toda la hazienda y nadie ha respirado; con que en llegando el tiempo procuraremos disponer nuevos arriendos de cassas y hacer los reparos que necesitaren porque si están derrotadas, además de ser principio de su perdición o no habrá quien las quiera arrendar o las quiera muy baratas ${ }^{30}$.

Para ello, durante este periodo pidieron préstamos por un total de 18.392 reales de vellón —el 48,5\% en forma de censo- . También aprovecharon la coyuntura para adquirir huertas, molinos y bosques que garantizaran la viabilidad de la casa bajo un régimen de arrendamiento. En este sentido, prefirieron las unidades de explotación completas a las piezas sueltas.

ES/AMMB/AM-020/002-01. Carta de Manuel de Sandoval a M. Teresa de san José, comendadora fechada en Logroño a 11 de febrero de 1736. Correspondencia 1637-1820. 


\section{Gráfico 3. Procedencia de los bienes raíces del convento de la Merced de Markina, 1583-1825}

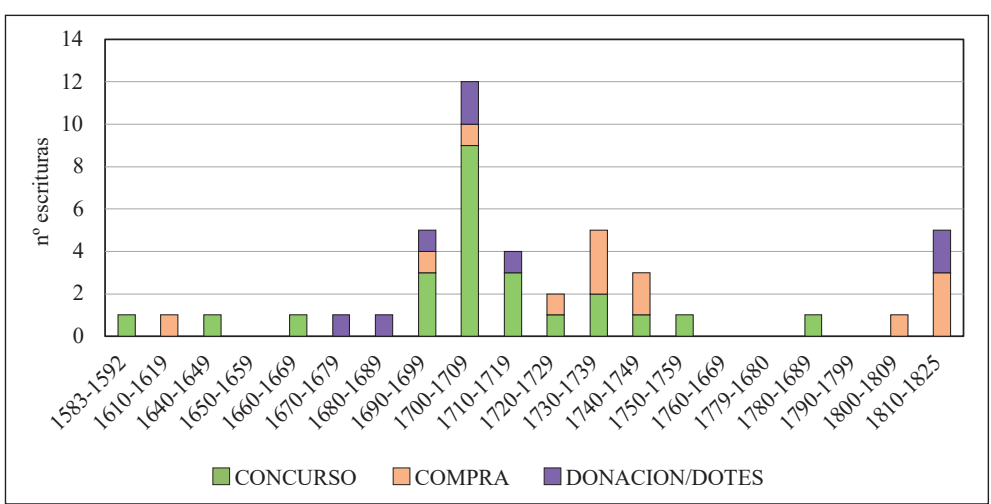

Fuente: Elaboración propia. ES/AMMB/AM-0003/004-00; AM-0011/001-00); AM-0010/003-00; AM-0012/001-00

El convento hizo un gran esfuerzo económico, comprometiendo buena parte de sus recursos en la financiación de obras de acondicionamiento y mejora de las fincas, como el drenaje de campos, cercamientos o mejora de los suelos con tratamientos de cal y estiércol. También cambiaron el uso de algunas parcelas desbrozando el terreno y preparándolo para la siembra o para plantar robles y castaños de uso carbonero. Se compraron bueyes, terneros y ovejas para explotarlos en régimen de aparcería, y dotaron de nuevas piedras al molino de Bolonchua. En las cuentas tomadas en 1738 el visitador escribía:

En el trienio de 1735-1738 se han pagado todas las deudas y no se debe nada. Se han reparado las caserías de Ybarguen, Elorriaga, Yurre, Oronzua, casa del indiano, Ubegui Ziarreta, casa de Logroño y la hacienda de viñas que hay allí, con un coste de 1.729 reales $^{31}$.

En definitiva, a partir de la década de 1740, la renta de tierras, caserías, ganado y explotación del bosque había sustituido casi por completo a la actividad crediticia y lo poco que quedaba de esta había cambiado por completo. Como sucediera en Santa Clara de Medina de Pomar y en otros conventos españoles, ahora se imponían pocos censos, aunque de capitales más abultados y con destino a hacer frente a las necesidades de los ayuntamientos.

31 ES/AMMB/AM-0012/001-00. 


\section{Conclusiones}

La composición patrimonial de los conventos estuvo condicionada por las necesidades de reproducción familiar de sus fundadores. Los de origen medieval contribuyeron de forma efectiva a la consolidación territorial y articulación del linaje fundador a través de la cesión de la titularidad, especialmente a sus abadesas, de señoríos y rentas. También reforzaron los lazos con sus respectivas ramas clientelares a través de la profesión de hijas, hermanas o viudas en un vínculo que sería tan efectivo como el matrimonial. Años más tarde, la fiebre fundacional de la reforma observante dio origen a multitud de conventos fundados por la hidalguía rural y urbana que buscaban un reconocimiento social y la posibilidad de perpetuar en manos de la familia el usufructo de aquellos bienes que no estaban comprometidos en el mayorazgo principal. La monetización de la economía y su adscripción a las órdenes mendicantes, que prohibían expresamente la posesión de bienes inmuebles, determinó la prevalencia de censos y juros en las economías conventuales.

Esta dualidad queda perfectamente reflejada en los dos casos analizados. El monasterio de Medina ejemplifica el modelo medieval fundado para preservar tierras, señoríos y vasallos, contribuyendo a consolidar el poder señorial en un territorio con un fuerte carácter estratégico desde un punto de vista comercial y militar. Por su parte, el de Markina refleja las dificultades a las que se enfrentaron los conventos vascos sujetos a la voluntad de un patrón que no siempre tuvo la solvencia necesaria para garantizar la continuidad de la fundación.

En ambos casos, la estrategia patrimonial y la gestión económica respondió a criterios de rentabilidad, mostrando todo el dinamismo posible en el marco de una economía preindustrial. En la época bajo medieval, el monasterio exigió el pago de dotes y legítimas en tierras o juros heredad. La búsqueda de una mayor productividad y eficiencia en la gestión de este patrimonio queda refrendada por la permuta o venta de las propiedades difíciles de administrar, por su calidad o lejanía. Con la llegada de la modernidad, las economías conventuales se monetizaron respondiendo a las nuevas oportunidades de inversión abiertas durante el siglo XVI, tanto en la esfera privada, con una fuerte demanda de capital, como en la pública, alentada por las necesidades financieras de la Corona. Los conventos fundados entonces basaron su economía en la adquisición de estos activos, que se ajustaban mejor al ideario observante. Esta corriente afectó también a los monasterios de origen medieval que comenzaron a exigir sus dotes en dinero, juros y censos. Las escasas propiedades adquiridas durante este periodo reflejan una cierta desafección por la explotación agrícola habida cuenta de su menor rentabilidad. Esta tendencia cambiará a finales del siglo XVII cuando el arreglo monetario contemple la reducción de los tipos de interés y los conventos vean 
peligrar la estabilidad de sus ingresos. A partir de entonces, se inició un proceso de adquisición de propiedades inmuebles, procedentes tanto del concurso de acreedores como de la inversión directa, lo que supuso un cambio en la estructura patrimonial basada en el aprovechamiento del entorno: caserías, bosques y ferrerías en el área cantábrica; molinos, aceñas y tierras de pan sembrar en el interior castellano; casas y pisos en las ciudades.

En definitiva, este estudio pone de manifiesto que sea cual fuere el origen y composición patrimonial de conventos y monasterios, su gestión fue presidida por criterios de rentabilidad económica mostrando una gran capacidad de adaptación a las diferentes coyunturas.

\section{AGRADECIMIENTOS}

Este trabajo ha sido posible gracias al Ministerio de Economía y Competitividad, que ha financiado el proyecto HAR2014-52434-C5-5-P, y también al Departamento de Educación, Universidades e Investigación del Gobierno Vasco, dentro del Programa de Financiación a Grupos de Investigación del Sistema Universitario Vasco, IT897-16. 


\section{Bibliografía}

Atienza López, Ángela (1988), Propiedad, explotación y rentas: el clero regular zaragozano en el siglo XVIII, Zaragoza, Departamento de Cultura y Educación.

Atienza López, Ángela (1989), «Transformaciones en el sistema de crédito y crisis de las economías monásticas a fines del Antiguo Régimen en Aragón», Comunicación presentada en el IV Congreso de la Asociación Española de Historia Económica, Alicante.

Atienza López, Ángela (2008), Tiempos de conventos. Una historia social de las fundaciones en la España Moderna, Madrid, Marcial Pons. $<$ https://www.jstor. org/stable/j.ctt6wptrh>.

Atienza LóPEZ, Ángela (2010), «La vida económica en los conventos femeninos en España durante la Edad Moderna. De una visión general a planteamientos más novedosos», Ariadna, 21, pp. 218-253.

Atienza López, Ángela (ed.) (ed., 2012a), Iglesia Memorable. Crónicas, historias, escritos... a mayor gloria. Siglos XVI-XVIII, Madrid, Sílex.

ATIENZA LóPEZ, Ángela (2012b), «El mundo de las monjas y de los claustros femeninos en la Edad Moderna. Perspectivas recientes y algunos retos», en Serrano, Eliseo (coord.), De la tierra al cielo: líneas recientes de investigación en historia moderna, vol. 1, Zaragoza, Fundación Española de Historia Moderna - Institución Fernando el Católico, pp. 89-108.

ATIENZA LóPEZ, Ángela (ed.) (ed., 2018), Mujeres entre el claustro y el siglo: autoridad y poder en el mundo religioso femenino, siglos XVI-XVIII, Madrid, Sílex.

ATIENZa LóPEZ, Ángela (2019), «No pueden ellos ver mejor...Autonomía, autoridad y sororidad en el gobierno de los claustros femeninos en la Edad Moderna», Arenal, 26 (1), pp. 5-34 <http://dx.doi.org/10.30827/arenal.v26i1.8538>.

Ayerbe Iribar, M. ${ }^{a}$ Rosa (2000), Catálogo documental del Archivo del Monasterio de Santa Clara, Medina de Pomar (Burgos) (1313-1968), Villarcayo, Monasterio de Santa Clara de Medina de Pomar.

Ballester, Adolfo (2005-2006), «Los censos: concepto y naturaleza», Espacio, Tiempo y Forma, Serie IV, Historia Moderna, t. 18-19, pp. 35-50. <https://doi. org/10.5944/etfiv.18-19.2005.3457>.

Beceiro PitA, Isabel (2014) «Los conventos de clarisas y sus patronas. Medina de Pomar, Palencia y Calabanzanos», Semata, Ciencias Sociais e Humanidades, 26, pp. 319-341. Recuperado de <http://www.usc.es/revistas/index.php/semata/ article/view/2021>.

BeCErro (1866), Libro de las Behetrías de Castilla mandado hacer por Pedro I de Castilla en el siglo XIV (edición 1886), Santander, Librería de Fabián Hernández. 
Burgo LóPEZ, CONCEPCIÓN (1993), «Política económica y gestión administrativa en las entidades monásticas femeninas» en Viforcos, $\mathrm{M}^{\mathrm{a}}$ Isabel; Paniagua, Jesús (coords.), I Congreso Internacional del Monacato femenino en España, Portugal y América, 1492-1992, tomo II, León, Servicio publicaciones Universidad de León, pp. 569-587.

Catalán Martínez, Elena (2000), El precio del Purgatorio. Los ingresos del clero vasco en la Edad Moderna, Bilbao, Servicio Editorial Universidad del País Vasco.

Clavero, Bartolomé (1974), Mayorazgo. Propiedad feudal en Castilla, 1369-1836, Madrid, Siglo XXI (ed. ampliada 1989).

CONSTITUCIONES (1624), Regla y Constituciones de las religiosas y monjas del Sagrado Orden de Nuestra Señora de la Merced, recopiladas por P. Melchor Prieto, Burgos, Pedro de Huydobro, 1624.

CONSTITUCiOnes (1662), Constituciones generales para todas las monjas y religiosas sujetas a la obediencia de la Orden de N.P. S. Francisco en toda la familia Cismontana, Madrid, Imprenta Real.

Domínguez Ortiz, Antonio (1960), Política y Hacienda de Felipe IV, Madrid, Pegaso (ed. 1983).

Domínguez Ortiz, Antonio (1973), Las clases privilegiadas en el Antiguo Régimen, Madrid, Itsmo.

García SÁEnz de Baranda, Julián (1917), Apuntes históricos sobre la ciudad de Medina de Pomar, Burgos, Tipografía de «El Monte Carmelo».

García SÁEnZ DE BARANDA, Julián (1926), «El convento de Santa Clara de Medina de Pomar y su señorío sobre los valles de Tudela y Relloso y el lugar de Cubillos del Rojo», Boletín de la Comisión Provincial de Monumentos Históricos y artísticos de Burgos, año 5, 17, pp. 101-109. < http://hdl.handle.net/10259.4/735>.

Gómez Navarro, Soledad (2007), «Patrimonio monástico y conventual en la España Moderna: Formas y fuentes de formación y consolidación», en Viforcos, $\mathrm{M}^{\mathrm{a}}$ Isabel; Loreto, Rosalva (coords.), Historias compartidas. Religiosidad y reclusión femenina en España, Portugal y América. Siglos XV-XIX, León, Universidad de León, pp. 435-465.

GóMEZ NAVARro, Soledad (2011), «De rejas adentro: Monjas y religiosas en la España Moderna. Una Historia de diferencias en la igualdad», Revista de Historia Moderna, 29, pp. 205-207. <https://doi.org/10.14198/RHM2011.29.09>.

Jular Pérez-Alfaro, Cristina (2001), «Nobleza y clientelas: el ejemplo de los Velasco», en Estepa, Carlos; Jular, Cristina (coords.), Los señoríos de Behetría, Madrid, CSIC, pp. 145-186.

LANDI, Fiorenzo (1998), Accumulation and dissolution of large estates of the regular clergy in Early Modern Europe, Rimini, Guaraldi. 
LANDI, Fiorenzo (2004), Confische e Sviluppo Capitalistico. I Grandi patrimônio del clero regolare in eta moderna in Europa e nel Continente Americano, Milano, FrancoAngeli.

LANZAgOrTA ArCo, M. José (2002), «La cultura de la pobreza en la vida conventual femenina: dos ejemplos de la orden Clariana. Santa María de la Bretonera (Belorado) y la Santísima Trinidad de Bidaurreta (Oñate)», Sancho el Sabio: Revista de cultura e investigación vasca, 16, pp. 31-46.

Llopis Agelán, Enrique (1980), Las economías monásticas al final del Antiguo Régimen en Extremadura, Tesis Doctoral Inédita. Universidad Complutense de Madrid. Acceso abierto en <https://eprints.ucm.es/52251/1/5309853115.pdf>.

López Martínez, Antonio L. (1992a), «Los juros de eclesiásticos: participación de los conventos andaluces en la Deuda Pública Castellana», Revista de Historia Económica-Journal of Iberian and Latin American Economic History, 10 (3), pp. 433-450. <https://doi.org/10.1017/S0212610900003591>.

López Martínez, Antonio L. (1992b), La economía de las órdenes religiosas en el antiguo Régimen: sus propiedades y rentas en el reino de Sevilla, Sevilla, Diputación Provincial.

López MarTíneZ, Antonio L. (1995), «Mecanismos y formación del patrimonio del clero regular en el reino de Sevilla durante el Antiguo Régimen. Criterios que presidieron la adquisición de sus propiedades», Actas del II Congreso de Historia de Andalucía. Andalucía Moderna (I), Córdoba, Publicaciones de la Consejería de cultura de la Junta de Andalucía y obra social y cultural Caja Sur, pp. 453-461.

LóPez MARTínez, Antonio L. (1997), «La empresa agraria monástica en Andalucía: gestión de las explotaciones agrarias de la Orden Cartuja (siglos XV-XIX)», Hispania, vol. 57, 196, pp. 709-729. <https://doi.org/10.3989/hispania.1997.v57. i196.690>.

López Martínez, Nicolás y GonzÁlez Terán, Emilio (2004), El monasterio de Santa Clara de Medina de Pomar. Fundación y patronazgo de la Casa de los Velasco, Burgos, Asociación Amigos del Monasterio de Santa Clara.

Martínez de Alarcón, Jerónimo (1692), «Memorial presentado a Carlos II por don Jerónimo Martínez de Alarcón, canónigo de Córdoba, en nombre de todas las iglesias catedrales de España y del Clero secular y regular de Castilla y de León, sobre que no se reduzca el interés de los censos que se pagaban al Estado eclesiástico», Real Academia de la Historia, 91.135, fol. 149-156. Recuperado de $<$ http://bibliotecadigital.rah.es/dgbrah/es/consulta/busqueda_referencia.cmd?ca mpo=idtitulo\&idValor $=41924>$.

Martínez RuIz, Enrique (dir., 2004), El peso de la Iglesia. Cuatro siglos de Órdenes religiosas en España, Madrid, Actas. 
MuÑoz, Fernando (2015), La provincia franciscana de Burgos en el Edad Moderna. Historia y representación, Tesis Doctoral Inédita, Universidad de La Rioja. Acceso abierto en $<$ https://dialnet.unirioja.es/servlet/tesis?codigo $=45459>$.

PAulino Montero, Elena (2013), «Patrocinio religioso, patrocinio artístico e identidad familiar a finales de la Edad Media. El caso de los Fernández de Velasco», eHumanista: Journal of Iberian Studies, 24, pp. 411-432. Recuperado de $<$ http:// www.ehumanista.ucsb.edu/volumes/24>.

PAz Moro, Agurtzane (2017), «Configuración patrimonial del monasterio de monjas dominicas de San Juan de Quejana, patronazgo del linaje de Ayala (1378-1524)», Hispania Sacra, LXIX, 139, pp. 101-115. <https://doi.org/10.3989/hs.2017.007>.

Reder Gadow, Marion (2000), «Las voces silenciosas de los claustros de clausura», en Cuadernos de Historia Moderna, 25, monográfico, pp. 279-335. Recuperado a partir de <https://revistas.ucm.es/index.php/CHMO/article/view/ CHMO0000220279A $>$.

Rey Castelao, Ofelia (1993), «Las economías monásticas femeninas ante la crisis del Antiguo Régimen», en Viforcos, $\mathrm{M}^{\mathrm{a}}$ Isabel; Paniagua, Jesús (coords.), I Congreso Internacional del Monacato femenino en España, Portugal y América, 14921992, tomo II, León, Servicio publicaciones Universidad de León, pp. 105-130.

Rey Castelao, Ofelia (2009), «Las economías eclesiásticas en la Edad Moderna: un estado de la cuestión», en Borderías, Cristina (ed.), Historia de las mujeres: perspectivas actuales, Barcelona, Icaria, pp. 197-223.

Ruiz de Loizaga, Saturnino (2007), «Conventos franciscanos en el norte de la provincia de Burgos a la luz de los diplomas pontificios (siglos XIII-XV)», en Sánchez, Domingo (coord.) Las Merindades de Castilla en la Historia, Medina de Pomar, Ayuntamiento de Medina de Pomar, pp. 251-292. Recuperado de $<$ http://www.saturninoruizdeloizaga.it/articoli.htm>.

SÁnchez LoRA, José Luis (1988), Mujeres, conventos y formas de la religiosidad barroca, Madrid, Fundación Universitaria Española.

SORIANo Triguero, Carmen (1994), «Los modos de subsistencia clarianos. Las fuentes de ingresos del convento de Santa Clara de Madrid (siglos XVII-XVIII)», Archivo Ibero-americano, n. ${ }^{\circ}$ 213-214, pp. 545-566.

Soriano Triguero, Carmen (2000), «La propiedad inmobiliaria de los conventos femeninos madrileños en el siglo XVIII», Cuadernos de Historia Moderna, n. $^{\circ}$ 24, pp. 11-31. Recuperado de <https://revistas.ucm.es/index.php/CHMO/article/ view/CHMO0000120011A>.

Toboso Sánchez, Pilar (1987), La deuda pública castellana durante el Antiguo Régimen (juros), Madrid, Instituto de Estudios Fiscales.

VIforcos, Ma Isabel y Loreto, Rosalva (coords., 2000), Historias compartidas. Religiosidad y reclusión femenina en España, Portugal y América. Siglos XV-XIX, León, Servicio de Publicaciones de la Universidad de León. 
